\title{
INNOVATION IN DESIGN THROUGH MATERIALS: THE PROJECT- BASED LEARNING (PBL) METHOD
}

\author{
B. Del Curto ${ }^{1}$, S. Lucibello ${ }^{2}$, L. Trebbi ${ }^{2}$ \\ ${ }^{1}$ Politecnico di Milano (ITALY) \\ ${ }^{2}$ Sapienza University of Rome (ITALY)
}

\begin{abstract}
The Paper illustrates a specific "joined teaching" experience - addressed to students with a miscellaneous background of the Master of Science in Product Design at Sapienza University of Rome - lead by a Materials Science and Engineering Professor from Politecnico di Milano and a Design Professor from Sapienza University of Rome. This "joined teaching" experience has been built on a strong interaction and hybridization between the methodologies of material science (deductivelogical-analytical) and design (inductive-experiential-synthetical). Such methodologies, as different in the research phase as in the educational one, have been hybridized resulting in a virtuous cycle able to connect the scientific research with the design of applications, and to create innovation in the field of product design such as in the field of materials science.

In the last decades, the role of material science in the design field has gone through a significant transformation, since materials went from being given entities upstream of the project, to be themselves something to design. Therefore, product innovation can arise from the quality of the idea as much as from the intrinsic quality of the material itself, leading to a convergence between materials and design. Employing the project-based learning (PBL) method, provides a significant opportunity for teaching design students a direct knowledge about concepts and principles of material science through the project, involving them in problem-solving, decision making and investigative activities, which culminate in the development of a realistic design concept.

The topic addressed by the Product design studio V course - Master of Science in Product Design Sapienza University of Rome, is "Translucency for living in the future", investigating the theme of translucency and its relation with light, both studied as physical-technical features and aestheticperceptual feature, able to determine design innovation. The topic is analyzed considering and identifying the four categories of Stratification, Brightness, Porosity and Thinness, sometimes interrelated, through which explore features and properties of translucent materials. The aim is to provide useful tools to know and understand innovation, interpret and imagine the qualities of materials in accordance with the project, merging lectures and a one-week immersion educational experience. The course has been organized in three phases: a preliminary activity consisting in lectures about analysis and tools, and culminating in the realization of a moodboard; a full-immersion workshop, during which conceiving and developing the design concept; and reviews on the final work development. The core of the whole course is the workshop, based on the PBL method that fosters collaborative work and enhances design thinking, shifting a huge portion of teaching activity from teacher-directed to "intentional learning" model. The workshop experience promotes cooperative learning, with the professors facilitation but not direction, taking great account of the important role of social interaction in learning. When working together in a situated activity, learners are able to develop a shared understanding of principles and ideas through back-and-forth sharing and debating of ideas, creating a "community of learners".
\end{abstract}

Keywords: design methodology, crossing disciplines, educational experience, materials science, product design innovation 


\section{STATE OF THE ART OF MATERIALS RESEARCH AND TEACHING}

From the early years of the $21^{\text {st }}$ century, there has been a burst of fresh interest from the Italian design culture in innovation with materials with regard to design activities and the ability for technical innovation to encompass design input and new qualities for future products. Technology and the sciences are expanding rapidly and new challenges are opening up (Ferrara and Lucibello, 2012). The Italian design culture's approach to technology and materials can be defined a "creative approach", which overcomes the traditional engineering-based approach bringing together classical and technical culture. Technological innovation and materials aren't seen solely as elements to be exploited in the creation of objects and part of a problem of constructive correctness, they are instead used as creative inputs and elements of the linguistic and poetic palette of a project. Hence the need to develop new teaching methods in order to allow comprehension and embracement of the changing technical scenario. They have to provide designers with an important critical capacity, providing the tools to deal with constantly evolving technological innovation and implement it in a way which aids users to exploit it. A pure technical and control-based outlook appears to be inappropriate in the design field. It is absolutely necessary to take into account the designer's need to combine technical and production matters with design-related elements for aesthetic experimentation on at least three levels: the level of perception, which reassesses the relationship of the senses during genuine experiences of things; the level of meanings, which emphasizes the importance of the cultural (artistic and conceptual) side of the relationship with technology; and the level of creativity, which uses the imagination to innovate and open up different scenarios compared to the past (Ferrara and Lucibello 2012).

An important contribution to the research in this area was made by Mike Ashby, professor from the Engineering Department at Cambridge University (Ashby, 2002). In his book, he explores and analyzes the different strategies used by designers in selecting materials, identifying how this strategies can be employed to give products their own character, an element as essential as functional aspects for the project's success. According to Ashby, designers and engineers represent two categories with a quite different approach which complement each other, underlining the need to establish a joint communication between them.

The last decades also saw the completion of a number of studies proposing theories and methods for the interpretation of the silent heritage of technical and cultural information enclosed in design products, with the objective of enhancing or redefining the educational approach.

Recently, Sabrina Lucibello and Marinella Ferarra developed a methodology for teaching materials in industrial design courses (Ferrara and Lucibello 2012). The research is based on a critical reflection upon the unique nature of Italian design's creative approach to technology, with the objective of bringing together teaching tools and methods able to embrace the peculiar characteristics of this approach, and to deal with the changes of the professional and socio-cultural context that teaching has to take on board. Taking the creative approach as starting point, the research looked into its effects on teaching materials for design, through data collection and analysis, interpretation and critical elaboration, and didactic experimentation.

Elvin Karana, Bahareh Barati, Valentina Rognoli and Anouk Z. van der Laan (Karana, et al, 2015) have developed the Material Driven Design (MDD) method, considering the material as a source of meaningful user experiences beyond its functional qualities, and qualifying it not only for what it is, but also for what it does, what it expresses to us, what it elicits from us, and what it makes us do. The method has been explored through a creative session on "designing with waste coffee grounds" conducted with Master's level design students at Politecnico di Milano in Italy, in order to develop a product concept starting from a not yet fully developed material.

Considering the material as the possible starting point of the design process, and the possibilities originated from the direct interaction of the designer with the material itself, has been again investigated by Valentina Rognoli through a course of the Master's level degree at Politecnico di Milano, where Do-It-Yourself Materials have been created and tested (Rognoli et al, 2016). The results highlight the strong contribution of the emotions, generated through the creation process of the material carried by the students, able to inspire the design process in a different way compared to the condition when materials are simply selected from an existing palette.

Beatrice Lerma, Claudia De Giorgi and Cristina Allione (Lerma et al, 2011) developed an assessment method for the sensory properties and environmental friendliness of materials, using a multi-criteria model and taking into account the different cultural contexts. The method uses the Sensotact ${ }^{\circ}$ SounBe ${ }^{\circledR}$, Eye-tracking, Sensotact $\AA$ and Gloss Scale tools to "measure" the sensory qualities of materials that enhance the use of products and aims to serve as a guide for the management of environmental sustainability aspects of products.

Júlio César Riccó Plácido da Silva and Maria do Rosário Gonçalves Mira (Silva and Mira, 2016), focused their research at Universidade Estadual Paulista (UNESP) in São Paulo, Brazil, on how 
thermographic tools and analysis about touch sensitivity and conductivity, are able to support the designer in gathering additional and deeper knowledge about users' interaction with materials, determining through a mapping process if the thermal conductivity factor can alter the materials' quality perception.

Bahareh Barati, Elvin Karana and Milou Foole from Delft University of Technology in The Netherlands, developed a real-time hybrid tool to support design students in "Experience prototyping" of an underdeveloped smart material composite (Barati et al, 2017). To compensate the knowledge gap encountered in approaching technologies still in an early development stage (composites of OLED technology and Piezoelectric polymer), which can't be adequately investigated by designers compared to fully developed ones, they used substituting technologies and techniques such as Electroluminescent Material Demonstrators and Chroma Key, in order to approximate and reproduce the materials experience, essential element for the exploration of the material development's potential.

\section{REFLECTION ON THE ITALIAN AND INTERNATIONAL APPROACHES TO TEACHING ABOUT TECHNOLOGY IN THE CONTEMPORARY WORLD}

Behind the development of a new didactic method for teaching materials and technologies for design, a comparative examination of the most significant and interesting national and international examples has been carried out.

Some of the most renowned north-european design schools, implemented an experimental approach for the study of materials focused on practical experience. A significant example is represented by the Design Academy in Eindhoven, where students are encouraged to develop critical thinking and creativity skills. Teaching is considered as guidance for student's personality, through which providing knowledge, skills and tools necessary to perform the design process, in its turn considered as the ability to organize the design research independently. Students indeed, are encouraged to make their own experimentations using their personal research method, testing and pushing to the limit new materials and techniques, thus going beyond the boundaries of current knowledge.

At Aalto University in Helsinki, design research is carried out through design practice with different projects including artistic research, design-driven exploration on emerging technologies and materials, and the action research-oriented development of new design methods and approaches. One of this research projects for instance, is conducted by the EMPIRICA group, whose approach involves as key-factors making, acting and engaging, and is focused on development of exploratory methods, where art and design related practices are used as research practice. The act of making plays an essential role in their research method, since is able to offer a valuable guidance both for reason and emotion, resulting in a dialogue between this two spheres. Moreover, designer's personality rather than expertise, is of great significance within the EMPIRICA research project, bringing an important contribution to the group's critical dialogue.

Individual experience and personality is taken into account also in the teaching approach by ENSClLes Ateliers in Paris, recognized for its innovative approach to design education based on diversity of student profiles, individualized programming and project based learning (PBL). Here, academic study is balanced with professional experience, and students are encouraged to develop their own profile, vision and path. Another essential aspect of ENSCl's approach is multidisciplinarity, in order to prepare students for the challenge of complexity, fostered by the proficiency of experts from different areas and joint programs with management, engineering and science schools.

These teaching and research experiences place the focus back on the creative and practical approach used when teaching about technique. There are multiple mentions of the combination of a technicaltheoretical approach and practical-experimental methods to foster creativity, as well as the ability to thrive in multidisciplinary and communicative spheres (Ferrara and Lucibello, 2012).

Going back in time, the Bauhaus approach is still considered a valuable reference model: based on a blend of practice and theory, with the teaching activities lead by two different masters, an artist and a craft worker. As Gropius explained, "it was necessary to have two different groups of teachers because it was not possible to find anyone suitable to lead the workshops: the artists did not have sufficient technical skills and the craftsmen did not have enough imagination for artistic matters" (Gropius, 1955). The guiding principle was to use craftsmanship not as a romantic ideal but as a didactic means to train modern designers.

Practical craft skills can aid understanding of materials, Bruno Munari believed that handling and tinkering with different materials can develop imagination in a logical process that requires inquisitiveness, attention, and the ability to act sensorily and give meaning to sensations (Ferrara and Lucibello, 2012). 
Alvar Aalto worked in a similar manner, when recording his experiments with curves in wood, he spoke of "abstract" trials with materials: "At the exhibition in London, we showed an aspect of our work for the first time: abstract experiments with wood processing. These experiments should more or less be seen as games with materials and technical, formal trials with any immediate practical goals. We believe that a rational road that leads directly to a practical aim is a negative thing for architects, as it can easily bring about formal mechanisms and vulgar rationalism" (Blaser, 1981).

From this reflection emerged the need to go beyond the actual organization of knowledge, still split into distinct disciplines, rearranging it into a multiverse able to embrace the multiple sides and skills of the profession. Therefore, is essential to adopt didactic methods which aim to develop creativity, in an overhaul involving a number of significant changes (Ferrara and Lucibello, 2012), introducing the following shifts:

1. From product to processes;

2. From problem solving to lateral thinking;

3. From definitions to meaning horizons;

4. From theories knowledge to hypothesis construction;

5. From sequential causality between teaching and learning to a systematic vision where teaching and learning may be asymmetrical and asynchronous;

6. From linear sequentiality of learning activities to holism and contextualization, in order to keep all of the doors of learning (different languages, different thinking approaches) open in a genuinely multimedia environment that encourages dialogue.

\section{THE CREATIVE APPROACH TO TECHNOLOGY (DIDACTIC METHOD)}

The study of materials can be faced from many different sides (from science and materials engineering skills to specific design skills), since it covers different research fields (from functional and performance qualities to perceptive and sensory properties) and requires various capabilities (from the appropriate use of materials to the ability to innovate by developing personal methods and visions of materials) (Ferrara and Lucibello, 2012). Consequently, the concerning teaching system has to manage such complexity, involving both the theoretical-analytical and the practical-experimental approach, in order to minimize the gap between theory and practice, developing analytical, design and communication skills of a figure that spans design areas, materials expertise, and metalanguages. The continual interaction between the ability to think and technical and creative activities leads to the development of technological skills (Kimbell, 1996).

The activities and objectives of the creative approach to technology can be summed up as follows:

1. Observe, analyse and understand.

2. Explore to start up creative processes.

3. Experiment, record and document in order to acquire a scientific method.

The didactic method used in this specific joined teaching experience, aims to hybridize the traditional approach of material science with the experimental procedures of design, architecture and communication. A key role is played by the application of the intentional learning model (inductive, synthetical and goal-driven), sided by deductive and teacher-directed learning activities.

The teaching experience was addressed to the students of Product design studio $V$ course of the Master of Science in Product Design at Sapienza University of Rome, integrated with the Design \& Technologies of Innovative Materials course and lead together by a Materials Science and Engineering Professor from Politecnico di Milano and a Design Professor from Sapienza University of Rome. The topic selected for the course was "Translucency for living in the future", in order to investigate the relationship between light and materials, and to study trans/ucency as both physicaltechnical and aesthetic-perceptual feature able to determine design innovation. A preliminary research phase around the topic led to the designation of some key-concepts subsequently translated into four sub-categories, sometimes interrelated, namely: Stratification, Brightness, Porosity and Thinness. The different ways through which translucency expresses itself have been analyzed and categorized, with the exploration and comparison of features and properties of translucent materials.

Following the principles of the creative approach to technology described before, the course has been structured in three main phases, each of which expected a students' delivery:

1. Analysis \& Tools: lectures concerning the course topic, from both the materials scientist and the designer perspective; brainstorming on translucency and the relative sub-categories, explored through references and examples in the field of architecture, interior, retail and exhibit 
design, product design and fashion; additional lectures by materials, colours, and technologies experts. At the end of this first phase students are supposed to present the results of the first delivery $1 A$ - design sheet (analysis of an existing design product related to translucency) and $1 B$ - concept, material \& technologies landscape (a physical or digital moodboard in order to better focusing on the concept and the inspiration around it);

2. WorkshopLab: one-week full-immersion workshop, during which the students (gathered in groups of three or four) are expected to conceive, develop and finally present a design concept, providing informations and hypothesis about materials and technologies (2nd delivery);

3. Final Work: reviews on the final work development, definition and presentation of the advanced design product scenario (3rd delivery).

\subsection{The Workshop}

During the first phase, students have the opportunity to observe, analyze and understand, acquiring and expanding their knowledge about materials and technologies alternating analytical-deductive learning typical of material science (from generalization and rules to specific examples) and synthetical-inductive learning (starting from specific references and examples). The core of the whole course however, is the full-immersion workshop, by means of which exploring translucency and the related sub-categories to start up the creative process, but also experiment, record and document using a scientific method in order to develop the concept. Shifting most of the teaching activities from teacher-directed lectures to Project-Based-Learning (PBL) method with the full-immersion workshop, allows to teach design students a direct knowledge about material science via the project, which is focused on topics, questions and problems that drive them to struggle with central concepts and principles of the discipline (Thomas, 2000). The learning activities are organized around the projects, defined in the literature as complex tasks, based on challenging questions or problems, that involve students in design, problem-solving, decision making, or investigative activities, give students the opportunity to work relatively autonomously over extended periods of time, and culminate in realistic products or presentations (Jones et al, 1997; Thomas et al, 1999).

The workshop proceeded the whole working day for one week, and was structured with daily tasks, useful for defining the guidelines in order to arrive at the concepts' development at the end of the week, according to the following phases: 1. Brainstorming; 2. Scenario; 3. Concept; 4. Final presentation.

\subsubsection{Brainstorming}
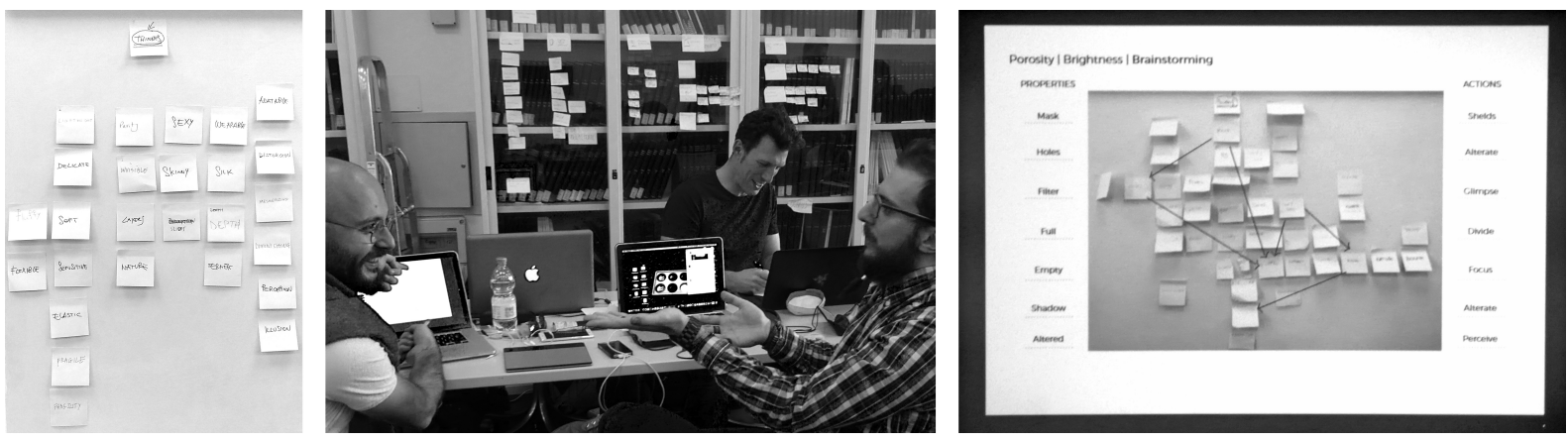

Figure 1. Brainstorming phase.

The workshop started with a collective brainstorming around translucency. Students were asked to point out emblematic keywords for each of the four categories related with the topic, identifying a wide range of actions, properties and feelings arisen from each student's personal experiences and emotions. The keywords were written down on adhesive notes and placed in one the four sections/categories, in order to be eventually rearranged after a collective debate. Thereafter, each group of students carried on the brainstorming individually, choosing one or two categories and selecting the most meaningful keywords according to their project with the help of the moodboards previously realized, identifying connections, paths and developing a mind map. At the end of this phase, each group discussed their ideas and outcomes together with the other participants. 


\subsubsection{Scenario}
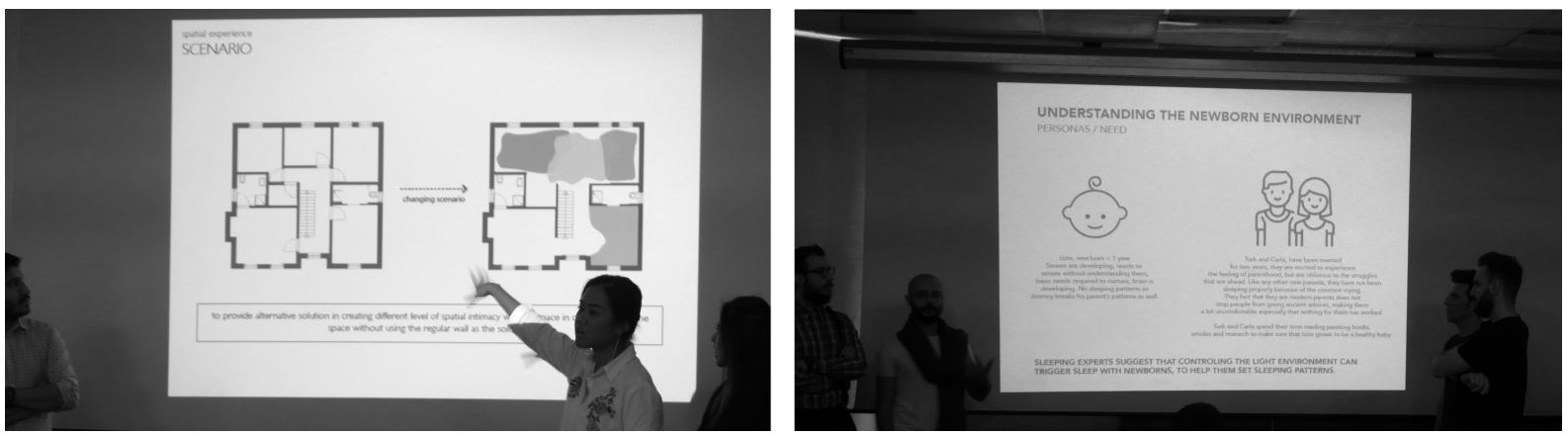

Figure 2. Conceiving the Scenario.

Once starting up the creative process with the first phase, the reflection/discussion moved on conceiving the possible scenario for the project, researching and analyzing needs, target, place of use and any other relevant information useful to identify and outline a clear and meaningful scenario. Like at the end of the first phase, also in this case working groups were asked to share their outcomes through a brief presentation, allowing professors and other students to ask questions, comment and give suggestions about it.

\subsubsection{Concept}
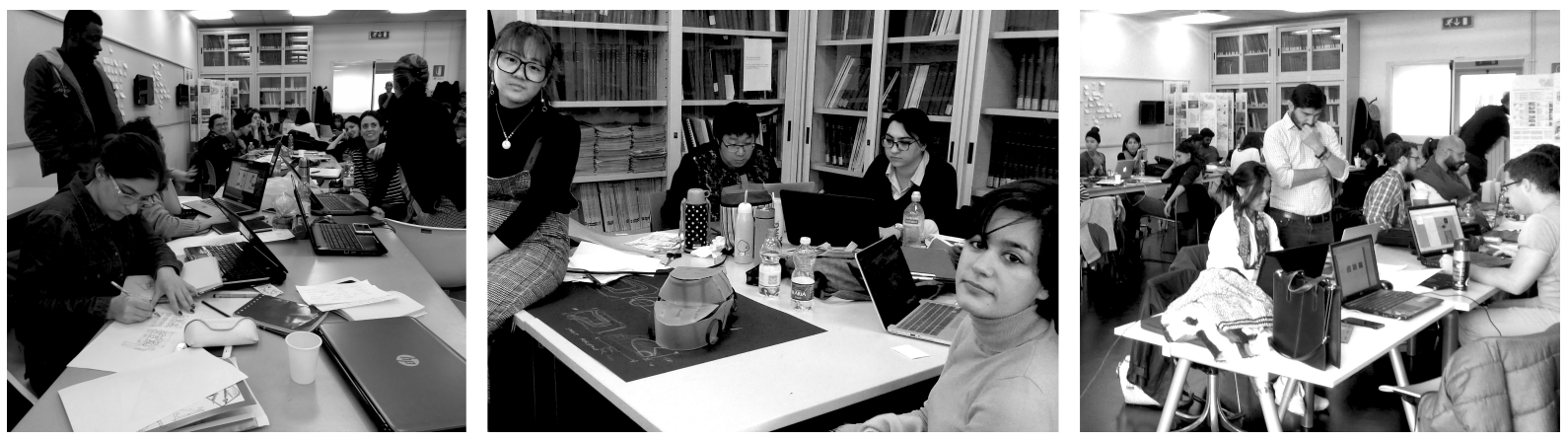

Figure 3. Developing the Concept.

After determining the scenario, groups started working on the concept development. Students had the possibility to conduct the project activities autonomously and freely through sketches, drawings and mockups, tinkering and experimenting with materials samples, and deepening analysis and researches of the previous phase, in order to conceive a design product. During the autonomous working time professors checked the groups' progresses from time to time with brief reviews as required. At the end of this phase, groups' outcomes were discussed and debated together with professors and other students, as for the previous ones.

\subsubsection{Final presentation}
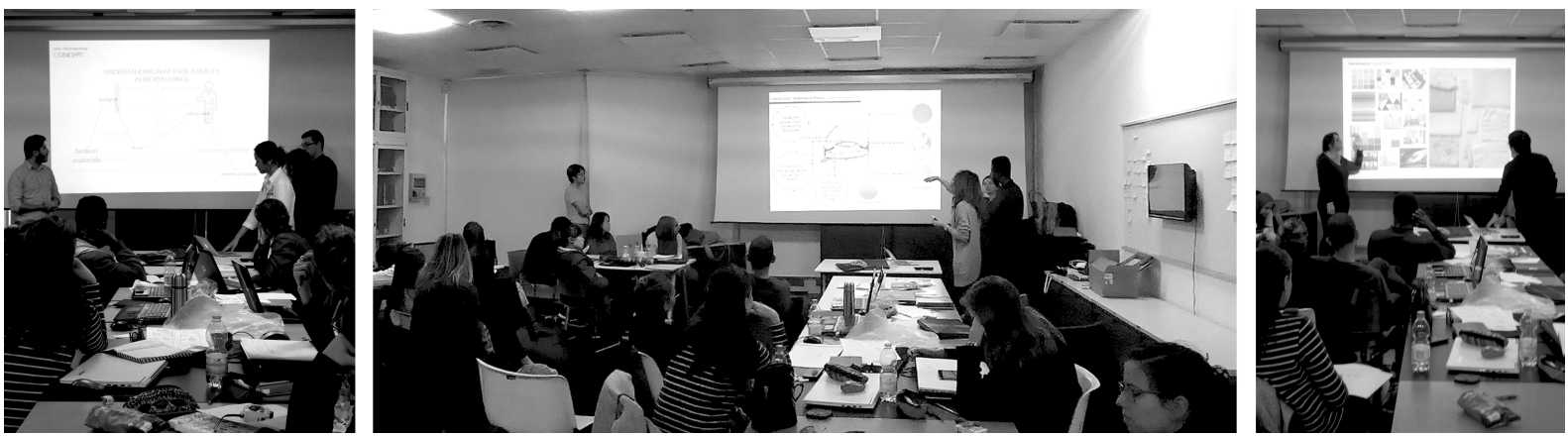

Figure 4. Projects presentation. 
Coming to the end of the workshop, in the last phase students finalized their design concepts, defined the main functions and features, and figured out the choice of materials for the projects. All the material produced during the workshop was then collected and organized by each group in a digital presentation in order to display their design concept and the whole path followed for its development, including mindmaps, sketches, storytelling and characterization of materials and functions. Groups' presentations were projected accompanied by an oral speech, and followed by professors' evaluations and suggestions, as well as a collective debate involving all the other students attending the workshop.

\section{4 “TRANSLUCENCY FOR LIVING IN THE FUTURE” COURSE}

The course topic, Translucency for living in the future, has been selected with the objective of providing students with useful tools to learn, understand and explore the know-how about innovation, as long as to interpret and imagine the material qualities in accordance with the project, and to investigate shapes and morphology in relation to physical and perceptive characteristics and available technologies. Expressing the immaterial and sensorial qualities of materials has become a fundamental aspect of materials selection for design products, and part of the design process' constraints; the attention dedicated to this aspect allows designers to turn the user experience into a deep and meaningful sensory interaction. For this reason is necessary to educate a professional figure able to handle both technical and humanistic knowledge about materials, technologies and their application.

The aim pursued with the employment of PBL method to the teaching of product design and material science was the transition from teaching materials for design to design with materials, integrating the technical-productive features with aesthetic and sensorial experimentation. This represents the overturning of the standard creative process (traditionally structured with the input of a need for turning it into a product), "catching" instead the essence of the material from the functional-performative, physical-structural and aesthetic-sensorial point of view, in order to induce and start up the creative thinking design process. Dealing with the project, highlights some driving questions around which students develop understanding of the central learning goals, granting a deeper conceptual comprehension than traditional didactic methods.

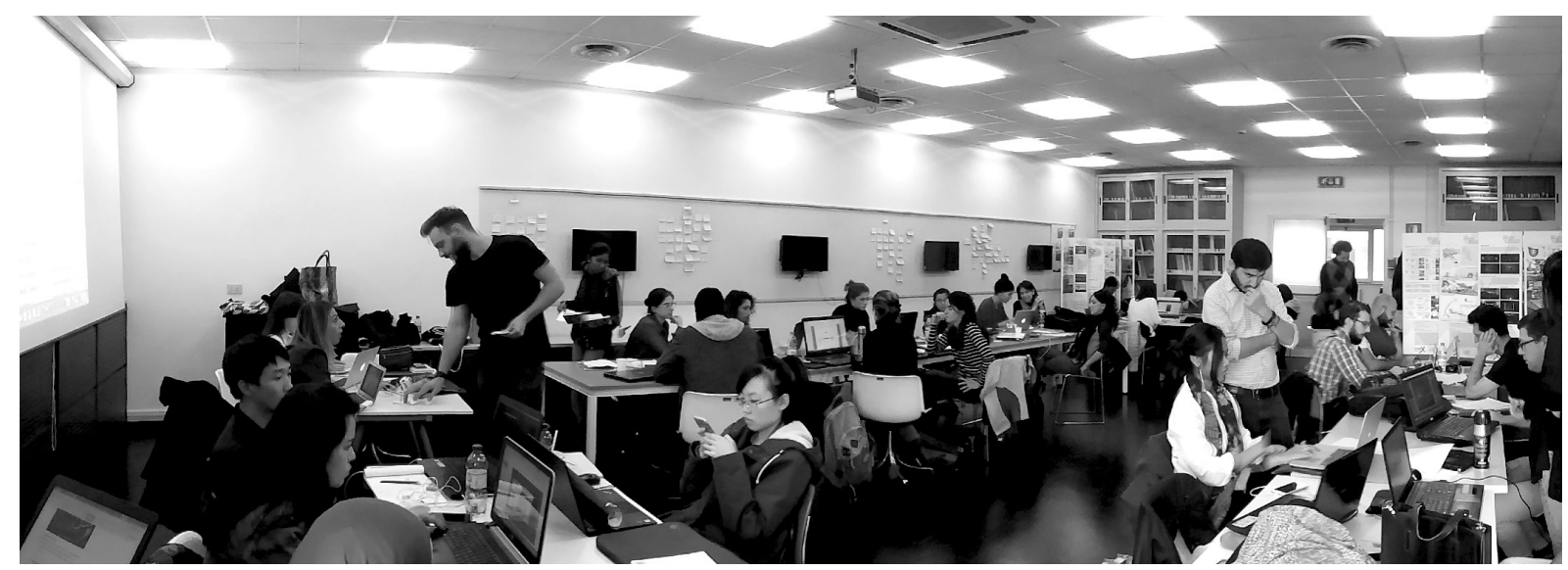

Figure 5. Translucency for living in the future workshop.

The results emerged from this "joined teaching" experience, highlight significant positive feedbacks. The cross-disciplinary approach has revealed strongly valuable for the teaching of material science and technologies through design projects with the PBL method as brought out above, furthermore the creation of artifacts during the workshop (physical and digital models, drawings and sketches, etc.), supported students in developing understanding related to different aspects of their projects. Artifacts stand for an external representation of their acquired knowledge, allowing students to construct and reconstruct their understanding. Being part of a workgroup requires the ability to function as a member of a team, which represents an essential skill for designers in the real-life experience, and allows the improvement of interpersonal, communication and leadership skills, as well as students' confidence; finally a fundamental emerged result was the importance of social interaction in learning, with professors and students working together to construct a shared understanding. Learners develop understanding of principles and ideas through sharing, using and debating ideas with others (Blumenfeld, 1996). During the workshop students collaborated with professors and other students to 
ask questions, form conclusions, make sense of information, discuss data and present findings and outcomes, receiving a constant feedback from professors, both collective and group-individual. This back-and forth sharing and debating of ideas and knowledge, led to the creation of a "community of learners" (Krajcik and Blumenfeld, 2006).

\section{REFERENCES}

References [Arial, 10-point, left alignment, upper and lower case] should be cited according to the Bibliography and Citation Style https://iated.org/citation_guide

[1] M. Ashby and K. Johnson, Materials and Design, the Art and Science of Materials Selection in Product Design. Oxford: Butterworth Heinemann, 2002.

[2] B. Barati and E. Karana, "Experience Prototyping Smart Material Composites", EKSIG2017: Alive. Active. Adaptive. Delft, the Netherlands, 2017.

[3] W. Blaser, Mobili di Alvar Aalto, p. 92, Milano: Electa, 1981.

[4] P. Blumenfeld, J.S. Krajcik, R. Marx and E. Soloway, "Lessons learned: A collaborative model for helping teachers learn project-based instruction”, Elementary school journal, vol. 94 (5), 1994.

[5] B. Del Curto, "The Importance of Materials and Technologies in Design", Proceedings of INTED Conference, Valencia, Spain, March 2009.

[6] P. D'Olivo, B. Del Curto, J. Faucheu, D. Lafon, J.F. Bassereau and D. Delafosse, "Education and Research: when design and engineering perform new links with the industrial world", Proceedings of INTED Conference, Valencia, Spain, 2013.

[7] A.J. Dutson, R.H. Todd, S.P. Magleby and C.D. Sorensen, "A Review of Literature on Teaching Engineering Design Through Project- Oriented Capstone Courses", Journal of Engineering Education, vol. 86, Issue 1, January 1997.

[8] C.L. Dym, A.M. Agogino, O. Eris, D.D. Frey and L.G. Leifer, "Eingeneering Design Thinking, Teaching and Learning", Journal of Engineering Education, vol. 94, Issue 1, January 2005.

[9] M. Ferrara and S. Lucibello, "Teaching material design. Research on teaching methodology about materials in industrial design", Strategic Design Research Journal, vol. 5, no. 2, pp. 7583, 2012.

[10] M. Ferrara and S. Lucibello, "Teaching material design", in Elena Maria Formia. Innovation in Design Education - Proceedings of the Third International Forum of Design as a Process, Torino, November 2012.

[11] W. Gropius, "My Conception of the Bauhaus Idea", in Scope of total Architecture, pp. 23-34, New York: Harper \& Row, 1955.

[12] E. Karana, B. Barati, V. Rognoli and A. Zeeuw van der Laan, "Material driven design (MDD): A method to design for material experiences", International Journal of Design, vol.9(2), pp. 35-54, 2015.

[13] E. Karana and P. Hekkert, "User- material-product interrelationships in attributing meanings", International Journal of Design, vol. 4(3), pp. 43-52, 2010.

[14] R. Kimbell, "Technology tasks and pupils learning", in A. Williams \& J.Williams - Technology education for teachers, Melbourne: Macmillan, 1996.

[15] J.S. Krajcik and P. Blumenfeld, "Project-based learning" in The Cambridge Handbook of Learning Sciences, pp. 317-333, New York, NY: Cambridge University Press, 2006.

[16] B. Lerma, C. De Giorgi and C. Allione, Design e materiali. Milano: Franco Angeli, 2011.

[17] E. Manzini, The Material of Invention. Cambridge, MA, USA: MIT Press, 1986.

[18] A. Piselli and B. Del Curto, "SMArt Design: un workshop didattico. Le leghe a memoria di forma nel progetto di artefatti connessi”, MD Journal, vol.2, 2016. 
[19] V. Rognoli, C. Ayala Garcia and S. Parisi, "The emotional value of Do-It-Yourself materials", Celebration \& Contemplation, 10th International Conference on Design \& Emotion, Amsterdam, the Netherlands, September 2016.

[20] J. Silva and M. Mira, "Thermography: supporting tool in the material research and product design", IFDP 2016 - Systems \& Design: Beyond Processes and Thinking, Valencia, 2016.

[21] J.W. Thomas, A review of research on project-based learning, PhD, California: Autodesk Foundation, 2000.

[22] J.W. Thomas, J.R. Mergendoller, and A. Michaelson, Project-based learning: A handbook for middle and high school teachers, Novato, CA: The Buck Institute for Education, 1999. 